\title{
Testing the Perturbation Sensitivity of Abortion-Crime Regressions
}

\author{
Michał Brzeziński, Maria Halber ${ }^{1}$
}

ABSTRACT

\begin{abstract}
The hypothesis that the legalisation of abortion contributed significantly to the reduction of crime in the United States in 1990s is one of the most prominent ideas from the recent "economics-made-fun" movement sparked by the book Freakonomics. This paper expands on the existing literature about the computational stability of abortion-crime regressions by testing the sensitivity of coefficients' estimates to small amounts of data perturbation. In contrast to previous studies, we use a new data set on crime correlates for each of the US states, the original model specifica-tion and estimation methodology, and an improved data perturbation algorithm. We find that the coefficients' estimates in abortion-crime regressions are not computationally stable and, therefore, are unreliable.
\end{abstract}

KEY WORDS: $\quad$ abortion, crime, computational stability, perturbation test

JEL Classification: $\quad$ C52, J13, K42

${ }^{1}$ University of Warsaw, Poland

\section{Introduction}

In a famous and controversial paper, Donohue and Levitt (2001), hereafter DL, argued that the legalisation of abortion in the United States (US) in the 1970s may account for as much as one-half of the overall crime reduction in the US in the 1990s. According to the theory behind this result, increased availability of abortion led to fewer unwanted children, who are more likely to become criminals when they reach adulthood. This hypothesis has become one of the most widely discussed ideas from Levitt and Dubner's (2005) Freakonomics, which was enormously popular among the general public.

DL's empirical analysis was criticised for various reasons by Joyce (2004; 2009), Lott and Whitley (2007), Foote and Goetz (2008), Moody and Marvell (2010) and others. Donohue and Levitt (2004; 2008)

Corespondence concerning to this article should be addressed to: mbrzezinski@wne.uw.edu.pl responded to some of these critiques; see also Joyce (2010) for a general overview of the debate about the impact of abortion on crime.

One recent criticism of DL's abortion-crime regressions involves testing the computational stability of their results using numerical analysis and computational economics tools. In particular, Anderson and Wells (2008) have argued that the computational problem posed in DL is ill-conditioned because it is very sensitive to small amounts of perturbation in the data, and therefore, their regression results are not computationally stable. Anderson and Wells (2008) showed that the condition number, $\kappa$, which is an upper bound for the sensitivity of the least squares solution to data perturbations, takes a very large value $(\kappa=1,329,930)$ for the basic regressions calculated by Donohue and Levitt (2001). Moreover, they calculated the bound on the relative error of the coefficients estimated by DL and found that it is too high to have any confidence in the estimated results. They concluded that there is not enough information in the data used by DL to mean- 

Table 1. Control variables and their numerical accuracy

\begin{tabular}{lll}
\hline Variable name & Definition & Reliable digits \\
\hline Abortion & "effective" abortion rate per 1,000 & 3 \\
Prisonpc & log(prisoners per capita), one year lagged & 3 \\
Policepc & log(police per capita), one year lagged & 3 \\
Unrate & unemployment rate & 6 \\
Rincpc & real income per capita & 2 \\
Prate & poverty rate & 5 \\
rwelpc15 & real welfare payments per capita, 15 years lagged \\
shall & shall-issue concealed weapons law & - \\
beerpc & beer consumption per capita
\end{tabular}

Notes: The data sources are provided in Moody and Marvell (2010). The number of reliable digits is taken from Mccullough (2010).

\section{Results}

Similar to DL's original study, we use fixed-effects models to estimate the relationship between abortion and the three types of crime. Regressions are weighted by state population. The coefficient for the abortion variable is negative and statistically significant with $p$-values less than 0.01 for all three models. The results of our perturbation sensitivity tests are presented in Figures 1-3, which show the Monte Carlo distributions of perturbed regression coefficients for the main independent variables. The number of replications is 9,999. The vertical lines in Figures 1-3 represent the values of the original (unperturbed) coefficients. The expectation is, if the unperturbed solution is computationally stable for the data set under review, that the unperturbed solution is close to the centre of the distribution for the perturbed coefficients. However, for almost all independent variables from the abortion-crime regressions studied, the unperturbed coefficients are clearly significantly different from the means of the simulated distributions. The $p$-values for the tests to determine whether the unperturbed solution is statistically equal to the average of perturbed solutions are always less than 0.001 .

Another simple test of computational stability using perturbed coefficients is to determine whether nearly all of the perturbed solutions agree with the unperturbed solution to at least one significant digit (Beaton et al., 1976). The definition of agreement to one significant digit is as follows. If $U$ is the unperturbed solution and $P$ is a perturbed solution, then $P$ is said to agree with $U$ if $P$ falls within the interval $U \pm$ five units in the second significant digit of $U$.

In cases where regression results are computationally stable, all or almost all the perturbed coefficients should agree with their unperturbed counterparts to at least the first significant digit. Table 2 shows results of the test based on this idea. The perturbed coefficients for the abortion and prison variables always agree to a single significant digit with the unperturbed solution. However, this is not the case for other variables. In particular, for the beerpc, prate and rincpc variables, on average, only $15 \%, 21 \%$ and $69 \%$, respectively, of perturbed coefficients agree with the unperturbed coefficients. In the case of the property crime equation, less than $1.5 \%$ of the simulated coefficients agree with the original coefficients for the policepc and rwelpc15 variables, which is clearly a sign that, for our data set, the original (unperturbed) solution for the DL's abortion-crime regressions is not computationally stable. 


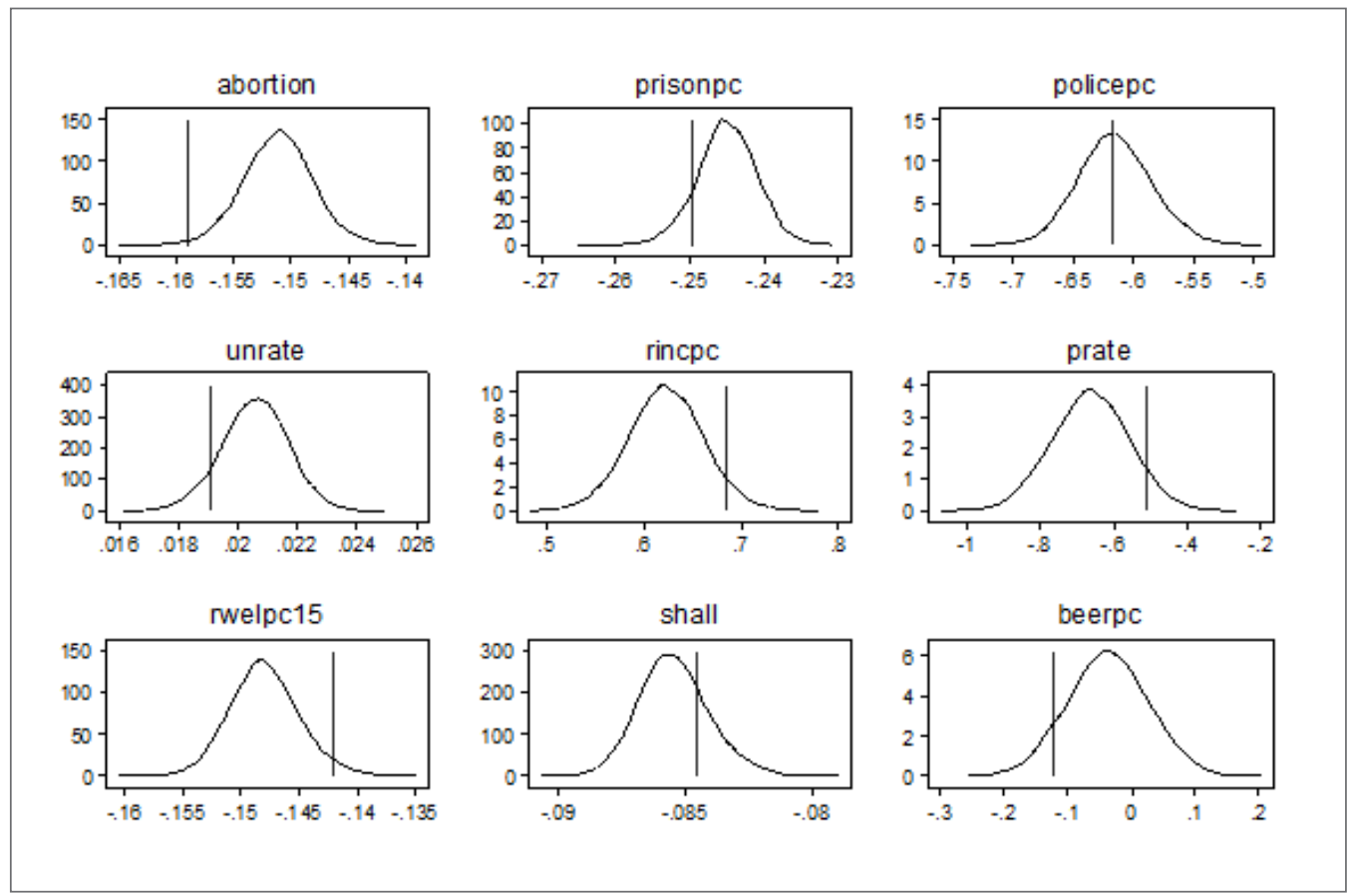

Figure 1. The Monte Carlo distribution of perturbed coefficients for the murder equation Notes: The vertical lines represent the values of the unperturbed coefficients.

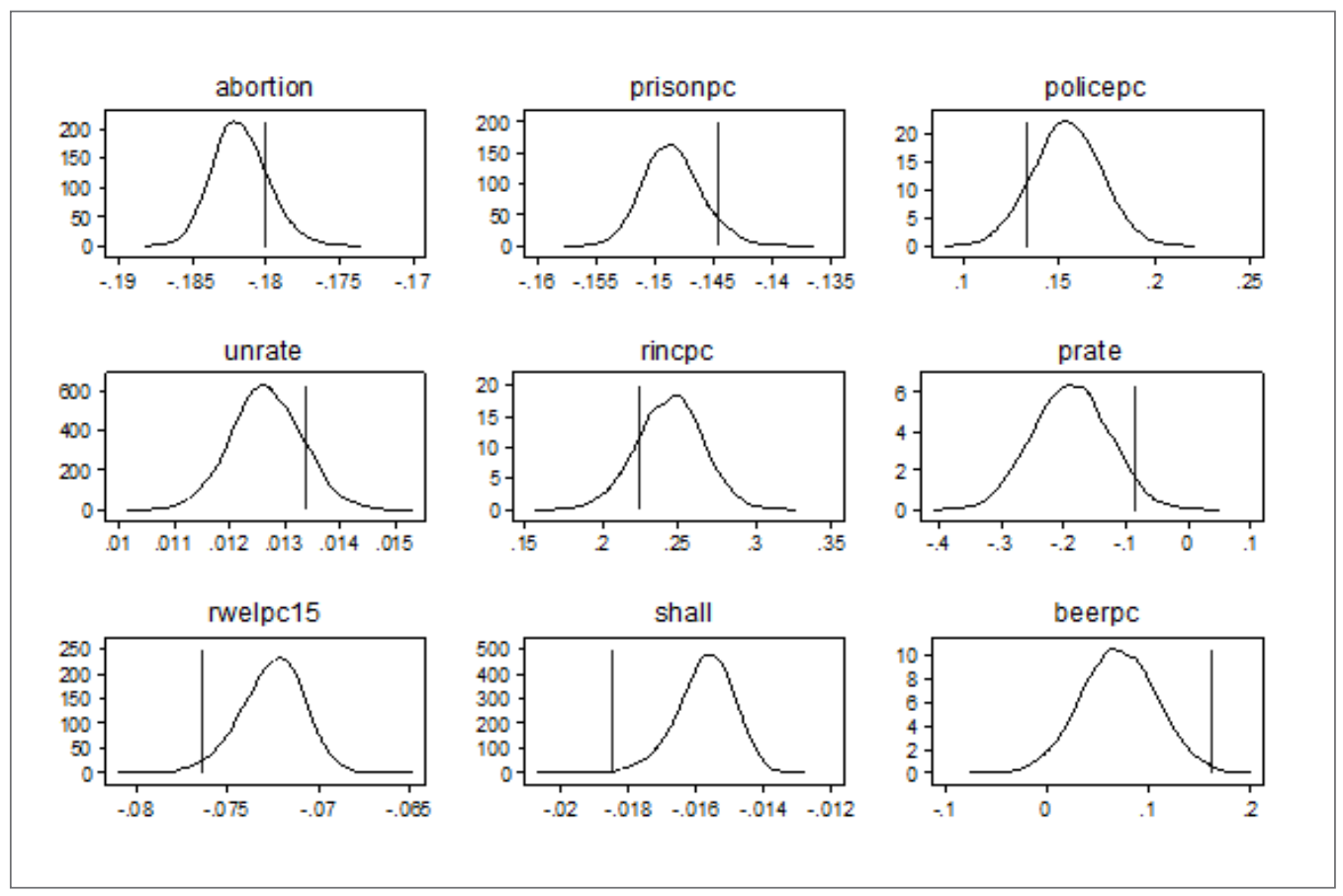

Figure 2. The Monte Carlo distribution of perturbed coefficients for the violent crime equation Notes: The vertical lines represent the values of the unperturbed coefficients. 


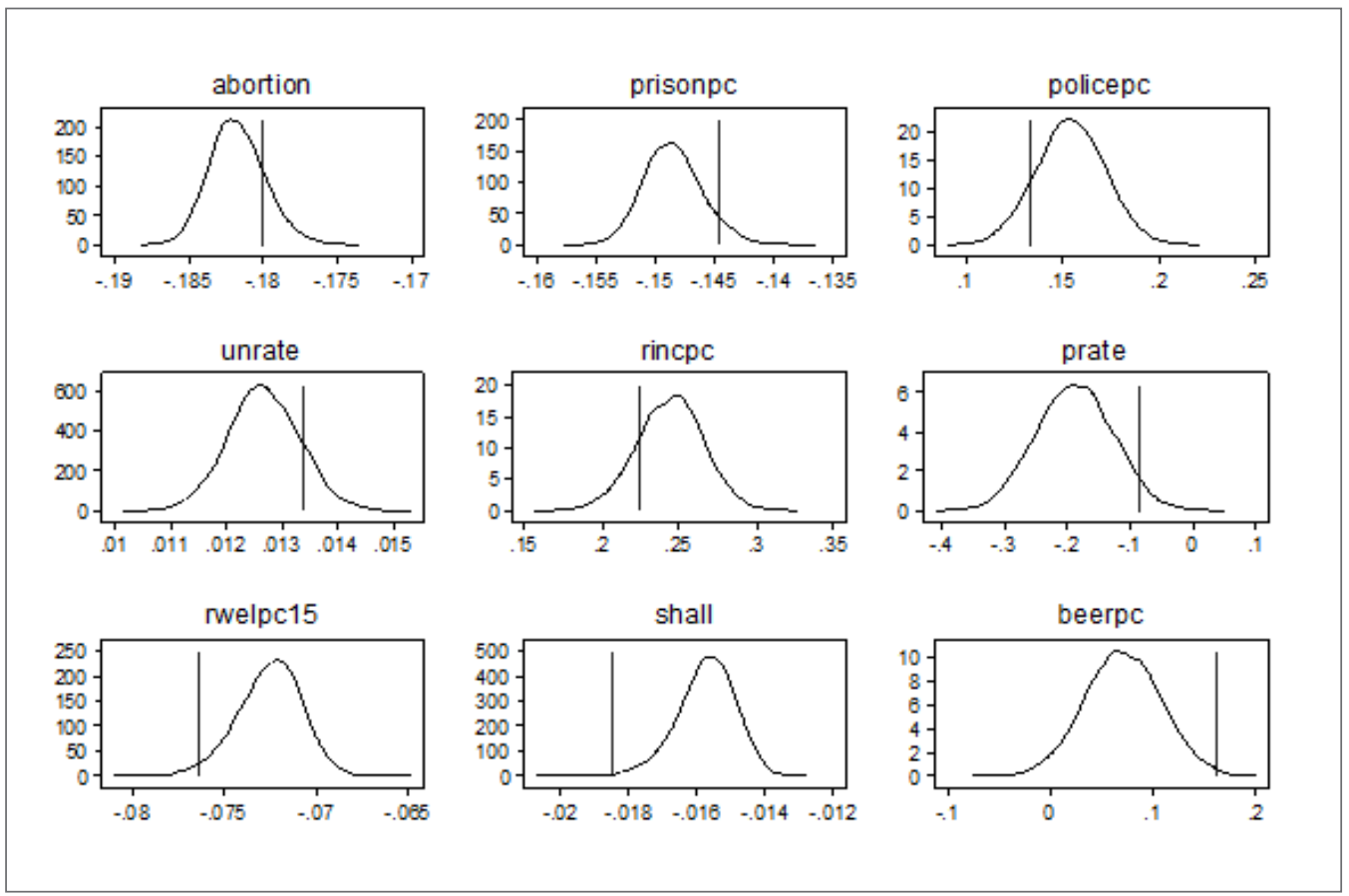

Figure 3. The Monte Carlo distribution of perturbed coefficients for the property crime equation Notes: The vertical lines represent the values of the unperturbed coefficients.

Table 2. Per cent of perturbed coefficients that agree with the unperturbed solution to at least one significant digit

\begin{tabular}{lccc}
\hline Variable & Murder & Violent crime & Property crime \\
\hline abortion & 100.00 & 100.00 & 100.00 \\
prisonpc & 100.00 & 100.00 & 100.00 \\
policepc & 89.54 & 94.92 & 0.79 \\
unrate & 99.94 & 100.00 & 100.00 \\
rincpc & 37.01 & 91.39 & 79.72 \\
prate & 13.76 & 1.78 & 46.02 \\
rwelpc15 & 100.00 & 73.25 & 1.30 \\
shall & 99.81 & 99.84 & 99.94 \\
beerpc & 27.19 & 13.44 & 5.68 \\
\hline
\end{tabular}




\section{Conclusions}

This paper tests the computational stability of Donohue and Levitt's (2001) abortion-crime regressions. We use their original model specification and estimation methodology, new quality data on state-level crime correlates in the United States provided by Moody and Marvell (2010), and an algorithm for generating perturbed data sets proposed by Vinod (2009). Our results confirm the conclusions in previous studies that Donohue and Levitt's (2001) approach does not provide computationally stable regression coefficients, and therefore, their estimates of the abortion-crime relationship are unreliable.

\section{References}

Anderson, W., \& Wells, M.T. (2008). Numerical Analysis in Least Squares Regression with an Application to the Abortion-Crime Debate. Journal of Empirical Legal Studies, 5(4), 647-681.

Beaton, A.E., Rubin, D.B., \& Barone, J.L. (1976). The acceptability of regression solutions: Another look at computational accuracy. Journal of the American Statistical Association, 71(353), 158-168.

Donohue, J.J., \& Levitt, S.D. (2008) Measurement Error, Legalized Abortion, and the Decline in Crime: A Response to Foote and Goetz. The Quarterly Journal of Economics, 123(1), 425-440.

Donohue, J.J., \& Levitt, S.D. (2004). Further Evidence that Legalized Abortion Lowered Crime: A Reply to Joyce. Journal of Human Resources, 39(1), 29-4.

Donohue, J.J., \& Levitt, S.D. (2001). The Impact Of Legalized Abrtion On Crime. Quarterly Journal of Economics, 116(2), 379-420.

Foote, C.L., \& Goetz, C.F. (2008). The Impact of Legalized Abortion on Crime: Comment. Quarterly Journal of Economics, 123(1), 407-423.

Joyce, T. (2009) A simple test of abortion and crime. The Review of Economics and Statistics, 91(1), 112-123.

Joyce, T. (2010). Abortion and Crime: A Review. In B. Benson \& P. Zimmerman (Eds.), The Handbook of the Economics of Crime (452-487). New York, NY: Edward Elgar.

Joyce, T. (2004). Did Legalized Abortion Lower Crime?. Journal of Human Resources, 39(1), 1-28.

Levitt, S.D., \& Dubner, S.J. (2005). Freakonomics: a rogue economist explores the hidden side of everything. New York, NY: William Morrow.
Lott, J.R., \& Whitley, J. (2007). Abortion and crime: unwanted children and out-of-wedlock births. Economic Inquiry, 45(2), 304.

McCullough, B.D. (2010). Econometric Computing with ' 'R". In H.D. Vinod (Ed.), Advances in Social Science Research Using R (1-21). New York, NY: Springer.

Moody, C.E., \& Marvell, T.B. (2010). On the Choice of Control Variables in the Crime Equation. Oxford Bulletin of Economics and Statistics, 72(5), 696-715.

Vinod, H.D. (2009). Stress testing of econometric results using archived code for replication. Journal of Economic and Social Measurement, 34(2), 205-217. 